Ann. Biol. anim. Bioch. Biophys., I967, 7 (I), 25-28.

\title{
ORIGINE DES SPERMATOZOÏDES DIPLOIDES PRÉSENTS DANS L'ÉJACULAT D'UN TAUREAU CHAROLAIS
}

\author{
C. ESNAULT, R. ORTAVANT \\ avec la collaboration technique de J.-C. Nicolle \\ Laboratoire de Physiologie de la Reproduction, \\ Centre de Recherches vétérinaires et zootechniques, 37 - Nouzilly
}

Différents auteurs (PAREz, Petel, et Vendrely, I960; Salisbury, Birge, de la TORRE et LODGE, Ig6I ; GLEDHILI, I964; SALISBURY et BAKER, I966) ont déjà signalé la présence, dans le sperme de taureaux de mauvaise fertilité, de spermatozoïdes dont la teneur en acide désoxyribonucléique (ADN) était double de la normale ; cependant l'origine de ces gamètes diploïdes n'a pu être déterminée avec certitude. Nous avons donc cherché à résoudre ce problème chez un taureau Charolais stérile présentant cette anomalie.

\section{MATÉRIEI, ET MÉTHODES}

Après castration unilatérale, des empreintes furent réalisées par apposition de petits fragments de testicule sur lames de quartz ou de verre, afin d'obtenir des noyaux bien séparés, en couche monocellulaire. La fixation fut pratiquée immédiatement dans un mélange alcool éthylique $95^{\circ} /$ acide acétique $(3 / \mathrm{r}, \mathrm{v} / \mathrm{v})$.

Les mesures furent faites à l'aide du microspectrophotomètre Universel Zeiss (UMSP I) selon la technique de CASPERSSON (1936):

I. Sur lames de quartz, après traitement par la ribonucléase (RNAase) (AmaNo, 1962) et montage dans la glycérine, en lumière monochromatique ultraviolette (longueur d'onde : 260 et $280 \mathrm{~m} \mu$ avec correction pour la lumière diffuse déterminée à $3 \mathbf{I} 5 \mathrm{~m} \mu$ ).

2. Sur lames de verre après coloration par la réaction de Feulgen, selon la technique décrite par LEUCHTENBERGER (1958) légèrement modifiée, à une longueur d'onde de $560 \mathrm{~m} \mu$.

Des frottis de spermatozoìdes, collectés au vagin artificiel et fixés aux vapeurs de formol, furent aussi mesurés de la même manière. 


\section{RÉSULTATS}

Les spermatozoïdes, présumés diploïdes, rencontrés dans les éjaculats (tab1. I), avaient, pour la plupart, la même apparence que ceux décrits par GLEDHIL (Ig64) mais présentaient assez souvent une pièce intermédiaire ou un flagelle double (fig. I); leur fréquence d'apparition était de I,73 p. mille.

\section{TABIEAU I}

Mesures microspectrophotométriques (extinction totale) des spermatozoïdes d'un taureau charolais stérile (Présence de spermatozoïdes diploïdes)

\begin{tabular}{|c|c|c|c|}
\hline Technique & $\begin{array}{c}\text { Spermatozoïdes } \\
\text { normaux }\end{array}$ & $\begin{array}{l}\text { Spermatozoïdes } \\
\text { anormaux } \\
\text { (diplö̈des) }\end{array}$ & $\begin{array}{l}\text { Rapport } \\
\text { diploïdes } \\
\text { normaux }\end{array}$ \\
\hline $\begin{array}{l}\text { Feulgen }(560 \mathrm{~m} \mu) \ldots \ldots \ldots \ldots \ldots \\
\text { UV }(260 \mathrm{~m} \mu) \ldots \ldots \ldots \ldots \ldots \ldots \\
\text { UV }(280 \mathrm{~m} \mu) \ldots \ldots \ldots \ldots \ldots \ldots\end{array}$ & $\begin{array}{l}7,26 \pm 0,110^{*}(20) \\
6,88 \pm 0,204(20) \\
4,21 \pm 0,133(20)\end{array}$ & $\begin{array}{r}13,94 \pm 0,189(20) \\
14,46 \pm 0,210(20) \\
8,65 \pm 0,269(20)\end{array}$ & $\begin{array}{l}1,92 \\
2,10 \\
2,05\end{array}$ \\
\hline
\end{tabular}

* Moyenne \pm erreur standard

( ) Nombre de mesures.

\section{TABLEAU 2}

Mesures microspectrophotométriques (extinction totale) des cellules germinales d'un taureau charolais stérile. (Présence de spermatides diploïdes)

\begin{tabular}{|c|c|c|c|c|}
\hline Technique & $\begin{array}{c}\text { Spermatocytes } \\
\text { primaires } \\
\text { Pachytène }\end{array}$ & $\begin{array}{l}\text { Spermatocytes } \\
\text { de } 2 \text { e ordre }\end{array}$ & $\begin{array}{c}\text { Spermatides } \\
\text { normales }\end{array}$ & $\begin{array}{l}\text { Spermatides } \\
\text { anormales }\end{array}$ \\
\hline $\begin{array}{l}\text { Feulgen }(560 \mathrm{~m} \mu) \ldots \ldots \\
\text { UV }(260 \mathrm{~m} \mu) \text { après RNAase } \\
\text { UV }(280 \mathrm{~m} \mu) \text { après RNAase }\end{array}$ & $\begin{array}{l}32,19 \pm 0,390^{*}(20) \\
35,67 \pm 1,027(20) \\
22,90 \pm 0,880(20)\end{array}$ & $\begin{array}{l}16,92 \pm 0,180(20) \\
17,42 \pm 0,823(3) \\
10,97 \pm 1,369(3)\end{array}$ & $\begin{array}{l}9,29 \pm 0,108(40) \\
8,56 \pm 0,250(20) \\
6,10 \pm 0,180(20)\end{array}$ & $\begin{array}{l}17,56 \pm 0,505(10) \\
15,10 \pm 0,705(10) \\
10,01 \pm 0,478(10)\end{array}$ \\
\hline
\end{tabular}

* Moyenne \pm erreur standard

( ) Nombre de mesures.

D'après le tableau 2 (empreintes de tissu testiculaire), on peut remarquer la présence de spermatides diploïdes aux stades $3-4-5$ du cycle de l'épithélium séminifère (classification ORTAVANT, I958) (fig. 2). Par contre, hous n'avons pu trouver de spermatocytes primaires ou secondaires montrant une teneur en ADN double de la valeur normale.

Le fait qu'un examen approfondi de coupes histologiques et d'empreintes ne nous ait pas permis de mettre en évidence de spermatocytes primaires ou secondaires 
à teneur en ADN ou protéines nucléaires anormale, laisserait penser que l'existence des spermatozoïdes diploïdes serait due à une transformation directe, sans deuxième division de maturation, des spermatocytes secondaires en spermatides et spermatozoides, plutôt qu'à une anomalie de synthèse de l'ADN. D'autres cellules que les spermatides

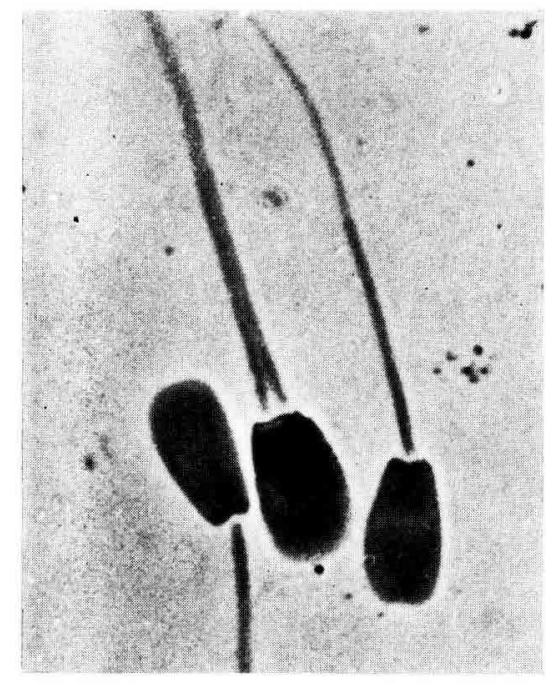

FIG. I - Spermatozö̈de diplö̈de encadréde deux spermatozoüdes normaux chez le Taureau. Présence d'une pièce intermédiaire double (Feulgen + Bleu de méthylène ; $\mathrm{G} \times 2480$ )

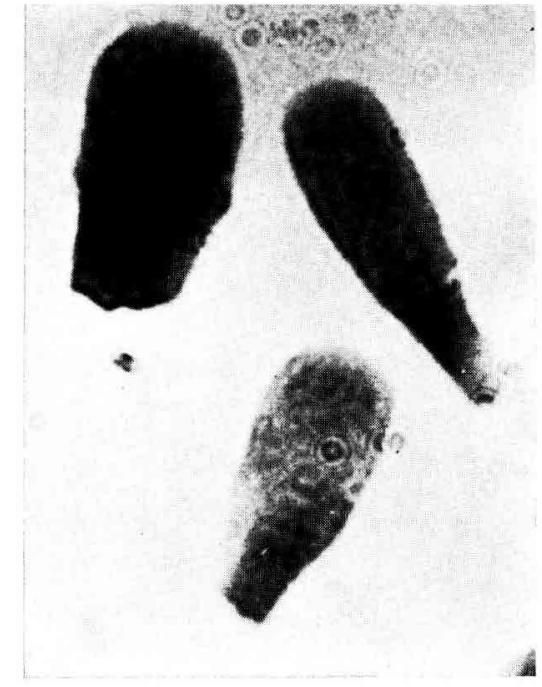

FIG. 2. - Spermatide diploide et spermatide normale chez le Taureau (Feulgen ; $\mathrm{G} \times 3$ 960)

pourraient donc subir l'évolution spermiogénétique. Cependant cette transformation serait associée à un très mauvais pouvoir fécondant de l'ensemble de la population des spermatozoïdes produits dans ces conditions.

Rę̧u pour publication en février 1967.

\section{SUMMARY}

ORIGIN OF DIPLOID SPERMATOZOA IN THE BULL

The DNA content of primary spermatocytes (pachytene stage), secondary spermatocytes and spermatids of a Charolais Bull with diploïd spermatozoa (I.73 p. Iooo was studied by UV absorption or feulgen coloration using a universal Zeiss microspectrophotometer (USMP I).

This chromosome abnormality occurs by suppression of the second meiotic division (table II).

\section{RÉFÉRENCES BIBLIOGRAPHIQUES}

Amano M., 1962. Improved techniques for the enzymatic extraction of nucleic acids from tissue sections. J. Histochem. Cytochem., 10, 204-212.

Caspersson T., I960. Úber den chemischen Aufbau der Strukturen des Zellkernes. Skand. Arch. Physiol., 73, Suppl. n०8. 
GLEDHILL B. L., 1964. Quantitative ultramicrospectrophotometry of presumed diploid bovine spermatozoa. Ve Congr. internation. Reprod. anim., 3, 489-494.

LeUChTENBERGER C., 1958. Quantitative determination of DNA in cells by Feulgen microspectrophotometry. General cylochemical methods, Acad. Press. inc., New York Ed. Danielli, v. I, 219.

Ortavant R., 1958. Le cyule spermatogénétique chez le Bélier. Thèse Doct. Paris, 127 pp.

Parez M., Petel J. P., Vendrely C., rg6o. Sur la teneur en acide désoxyribonucléique des spermatozoìdes de taureaux présentant différents degrés de fécondité. C. R. Acad. Sci., 251, 2581-2583.

Salisbury G. W., Birge W. J., de la Torre L., Lodge J. R., I96I. Decrease in nuclear Feulgen-positive material (DNA) upon ageing in in vitro storage of bovine spermatozoa. J. biophys. biochem. Cytol., 10, 353-359.

Salisbury G. W., Baker F. N., 1966. Frequency of occurence of diploid bovine spermatozoa. J. Reprod. Fert., 11, 477-480. 